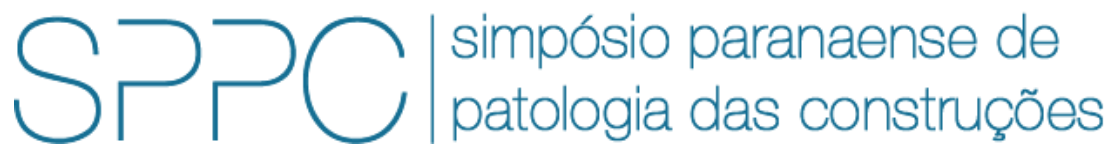

ISSN 2526-7248 artigo 2SPPC1018, pp. 213-223, 2017

\title{
Avaliação da pozolanicidade do pó de cerâmica vermelha e seu efeito mitigador do ataque por sulfatos de sódio em barras de argamassa
}

\author{
Fernanda Brekailo ${ }^{1}$, Elias Pereira ${ }^{2}$ e Eduardo Pereira ${ }^{3}$ \\ ${ }^{1}$ Graduanda em Engenharia Civil, Universidade Estadual de Ponta Grossa, \\ nandabrekailo@hotmail.com
}

2 Engenheiro Mestrando, Universidade Estadual de Ponta Grossa, elias_pereira@outlook.com

${ }^{3}$ Doutor, Universidade Estadual de Ponta Grossa, eduardopereira@uepg.br

Resumo: A incorporação de adições minerais ao cimento provoca alterações na microestrutura de compósitos cimentícios, podendo mitigar a degradação ocasionada pelo ataque por sulfatos. Neste trabalho realizou-se o estudo de reaproveitamento de resíduo de cerâmica vermelha como adição mineral e seu efeito mitigador do ataque por sulfatos. Apesar de a cerâmica atender aos requisitos químicos, o material não atendeu requisitos mínimos no ensaio de Chapelle modificado e de IAP com $\mathrm{cal}$, e também não apresentou resultados que indiquem reatividade pozolânica na DRX. Na determinação da variação dimensional de barras de argamassa, as diferentes porcentagens de substituição da adição mineral na composição do material ligante apresentaram expansões maiores que a argamassa de referência, não possuindo, portanto capacidade de mitigar o ataque por sulfatos.

Palavras-chave: Adição mineral; Pó de cerâmica vermelha; Argamassa; Ataque por sulfatos.

Abstract: The addition of minerals to the cement causes changes in the microstructure of cement composites, and is able to mitigate the degradation caused by sulfate attack. In the present article were performed studies on the reutilization of red ceramic residue as a mineral addition and its mitigating effect against the sulfate attack. Although the ceramics met the chemical requirements, the material did not meet minimum requirements in the modified Chapelle test and the Pozzolanic Activity Index made with lime, and also did not present results indicating pozzolanic reactivity in XRD. In the determination of the dimensional variation of mortar bars, the different percentages of substitution of the mineral addition in the composition of the binding material presented larger expansions than those at the reference mortar, therefore not having the capacity of mitigating the sulfate attack.

Keywords: Mineral addition; Ceramic powder red; Mortar; Sulphate attack. 
BREKAILO, F.; PEREIRA, E.; PEREIRA, E., POTENCIAL POZOLÂNICO DO PÓ DE CERÂMICA VERMELHA E SEU EFEITO MITIGADOR DO ATAQUE POR SULFATOS DE SÓDIO EM BARRAS DE ARGAMASSA. $2^{\circ}$ Simpósio Paranaense de Patologia das Construções (20 SPPC), artigo 2SPPC1018, pp. 213-223, 2017. DOI: 10.4322/2SPPC.2017.018

\section{Introdução}

O concreto deve ser capaz de resistir aos processos de deterioração devido aos agentes agressivos do meio, mantendo a capacidade de desempenhar sua função prevista, preservando sua forma, resistência e condição de utilização [1-2]. Os processos de deterioração podem ter origem em fenômenos físicos, químicos ou mecânicos, mas raramente possuem uma única causa, podendo ocorrer processos físicos e químicos simultaneamente [2-3].

O ataque por sulfatos é um dos fenômenos que pode ocasionar a degradação do concreto. A presença dos íons $\mathrm{SO}_{4}{ }^{2-}$ na solução dos poros resulta em reação com o hidróxido de cálcio (portlandita), silicato de cálcio hidratado (CSH) e o monossulfoaluminato de cálcio hidratado (AFm), formando gipsita, etringita secundária (AFt) e, também, em casos específicos, a taumasita, dependendo do tipo de cátion associado à solução de sulfato de sódio [1-3]. A expansão e a ruptura que ocorre no concreto pelo ataque de sulfato se devem ao fato de tanto a gipsita como a etringita formada ocuparem um volume maior do que os compostos que elas substituíram [4]. Além disso, pode ocorrer perda de massa e diminuição progressiva da resistência devido a perda da coesão dos produtos da hidratação do cimento [1]. A concentração de íons nos poros, a composição do cimento, a permeabilidade e a absorção capilar de água da matriz são fatores determinantes do grau de degradação por expansão, fissuração e perda de massa [3]. Reduzindo, por exemplo, a permeabilidade do concreto pode-se diminuir a degradação ocasionada pelo ataque por sulfatos [5].

O uso de adições minerais junto ao material ligante provoca alterações de natureza química e física no concreto que definem o seu desempenho. A microestrutura do concreto é modificada, o que altera a porosidade da matriz hidratada. Isso ocorre pelo efeito fíler, devido à presença de pequenas partículas que podem ocupar os vazios, unido às reações pozolânicas [3-6]. Além disso, a incorporação de adições minerais na composição do material ligante traz benefícios econômicos e ambientais, pois assim preservam-se recursos naturais pelo reuso de um passivo ambiental e se reduz o consumo de energia, questões muito importantes no ramo da indústria da construção civil, que possui elevado impacto ambiental [7]. O objetivo do presente trabalho foi realizar o estudo de uma alternativa de aproveitamento de resíduo de cerâmica vermelha, proveniente de tijolos e blocos cerâmicos, avaliando sua potencialidade pozolânica e sua capacidade de mitigação do ataque por sulfatos de origem externa.

\section{Materiais e Métodos}

Para avaliar o efeito da incorporação de resíduo de cerâmica vermelha em compósito de cimento Portland utilizou-se um material cerâmico oriundo de rejeitos de blocos cerâmicos (tijolos de cerâmica vermelha). Os blocos passaram por um pré-beneficiamento em equipamento de abrasão Los Angeles e o resultante foi peneirado para obtenção de pulverulento. O material final é o passante na peneira 200 (abertura de 0,075 mm).

A análise do material cerâmico iniciou-se pela determinação da sua massa específica conforme NM 23 [8]. O material foi caracterizado por difratometria de 
BREKAILO, F.; PEREIRA, E.; PEREIRA, E., POTENCIAL POZOLÂNICO DO PÓ DE CERÂMICA VERMELHA E SEU EFEITO MITIGADOR DO ATAQUE POR SULFATOS DE SÓDIO EM BARRAS DE ARGAMASSA. $2^{\circ}$ Simpósio Paranaense de Patologia das Construções (20 SPPC), artigo 2SPPC1018, pp. 213-223, 2017. DOI: 10.4322/2SPPC.2017.018

raios-X (DRX) para identificação das fases cristalinas e, também, do halo amorfo que sinaliza a reatividade das adições. Procedeu-se também a determinação do teor de hidróxido fixado pelo método Chapelle modificado conforme NBR 15895 [9] e análise química por FRX.

A caracterização quanto à reatividade pozolânica foi feita seguindo procedimento sugeridos na NBR 5751 [10] - Índice de atividade pozolânica (IAP) com cal e NBR 5752 [11] - Índice de desempenho (ID) com cimento. A Tabela 1 apresenta as proporções de mistura das argamassas em massa para determinação do índice de atividade pozolânica com cal e do índice de desempenho com cimento, sendo que na determinação do ID com cimento a consistência da argamassa B não foi corrigida pela falta de aditivo superplastificante.

Tabela 1: Proporção de mistura das argamassas para IAP com cal e ID com cimento.

\begin{tabular}{c|c|c|c|c|c}
\hline \multirow{2}{*}{ Argamassas } & \multicolumn{5}{|c}{ Massa dos materiais (g) } \\
\cline { 2 - 6 } & Cimento & $\begin{array}{c}\text { Hidróxido } \\
\text { de cálcio }\end{array}$ & $\begin{array}{c}\text { Areia } \\
\text { normal }\end{array}$ & $\begin{array}{c}\text { Material } \\
\text { cerâmico }\end{array}$ & Água \\
\hline Argamassa para IAP com cal & - & 208 & 1872 & 476,36 & 540,2 \\
\hline Argamassa A para ID com cimento & 624 & - & 1872 & - & 300 \\
\hline Argamassa B para ID com cimento & 468 & - & 1872 & 156 & 300 \\
\hline
\end{tabular}

O material cerâmico foi também utilizado como substituição parcial ao cimento em argamassas e avaliadas quanto ao potencial de mitigação ao ataque por sulfatos em solução de sulfato de sódio. A metodologia utilizada foi a proposta pela NBR 13583 [12]. Neste caso, foram estudados 5 traços, cada um com diferentes porcentagens de substituição: referência (sem adição), 3\%, 5\%, 12\% e 20\%. A argamassa sem substituição foi utilizada como argamassa de referência. Os valores de 3 e $5 \%$ foram adotados baseando-se no limite máximo de material fino passante na peneira de abertura $0,075 \mathrm{~mm}$ que pode estar presente no agregado miúdo, valores estes determinados pela NBR 7211 [13]. O limite de $12 \%$ foi adotado considerando que 0 material cerâmico é constituído totalmente de grãos gerados durante a britagem, 0 que altera o limite máximo de material fino passante que pode estar presente no agregado miúdo, conforme determinado também pela NBR 7211 [13]. O valor de $20 \%$ de substituição foi adotado com base na quantidade máxima de material fino passante que pode estar presente no agregado miúdo de agregado reciclado da classe ARM, determinado na NBR 15116 [14]. A Tabela 2 apresenta as proporções de mistura das argamassas em massa para as diferentes porcentagens da adição mineral.

Tabela 2: Proporção de mistura das argamassas para avaliação do potencial de mitigação ao ataque por sulfatos em solução de sulfato de sódio.

\begin{tabular}{|c|c|c|c|c|}
\hline \multirow[b]{2}{*}{ Argamassas } & \multicolumn{4}{|c|}{ Massa dos materiais (g) } \\
\hline & Cimento & $\begin{array}{c}\text { Areia } \\
\text { normal }\end{array}$ & $\begin{array}{l}\text { Material } \\
\text { Cerâmico }\end{array}$ & Água \\
\hline Argamassa com $0 \%$ de substituição & 750 & \multirow{5}{*}{2400} & - & \multirow{5}{*}{450} \\
\hline Argamassa com $3 \%$ de substituição & 727,5 & & 22,5 & \\
\hline Argamassa com 5\% de substituição & 712,5 & & 37,5 & \\
\hline Argamassa com $12 \%$ de substituição & 660 & & 90 & \\
\hline Argamassa com $20 \%$ de substituição & 600 & & 150 & \\
\hline
\end{tabular}

Para os ensaios de índice de atividade pozolânica com cal e com cimento e avaliação quanto ao potencial de mitigação ao ataque por sulfatos em solução de 
sulfato de sódio foi constituída a granulometria do agregado miúdo por meio do peneiramento da areia do rio Tibagi, disponível na região. A granulometria foi composta por 4 frações iguais da série normal, sendo elas as frações retidas nas peneiras \#16, \#30, \#50 e \#100, conforme a NBR 7214 [15]. O cimento Portland utilizado foi do tipo CPIIF-40. O hidróxido de cálcio PA foi produzido pelo fabricante Dinâmica ${ }^{\circledR}$ Química Contemporânea Ltda. e o sulfato de sódio PA pelo Fmaia®. A mistura dos materiais nestes ensaios foi feita conforme recomendações da NBR 7215 [16], porém os materiais secos foram misturados e homogeneizados antes de serem colocados na argamassadeira para garantir que a adição, que é um pó muito fino, estivesse bem misturada aos materiais e evitar a formação de grumos.

\section{Resultados e Discussão}

Os resultados da caracterização físico-química do cimento Portland está apresentada na Tabela 3 e todos índices apresentam valores dentro dos limites da especificação.

Tabela 3: Caracterização físico química do cimento CPII-F-40.

\begin{tabular}{|c|c|c|c|c|c|c|c|c|c|c|c|}
\hline \multicolumn{12}{|c|}{ Ensaios Químicos } \\
\hline \multicolumn{3}{|c|}{$\begin{array}{c}\text { Perda ao Fogo } \\
\%\end{array}$} & \multicolumn{3}{|c|}{$\begin{array}{c}\mathrm{MgO} \\
\%\end{array}$} & \multicolumn{2}{|r|}{$\mathrm{SO}_{3}$} & \multicolumn{4}{|c|}{$\begin{array}{c}\text { Resíduo Insolúvel } \\
\%\end{array}$} \\
\hline \multicolumn{3}{|c|}{4,59} & & 6,21 & & & 3,21 & & & 0,99 & \\
\hline \multicolumn{12}{|c|}{ Ensaios Físicos } \\
\hline \multirow{2}{*}{$\begin{array}{l}\text { Massa } \\
\text { Espec }\end{array}$} & \multicolumn{2}{|c|}{ Finura } & \multirow[b]{2}{*}{ Blaine } & \multirow{2}{*}{$\begin{array}{c}\text { Água } \\
\text { de } \\
\text { Consist }\end{array}$} & \multicolumn{2}{|c|}{ Tempo Pega } & \multirow{2}{*}{$\begin{array}{l}\text { Exp. } \\
\text { Quent } \\
\text { e }\end{array}$} & \multicolumn{4}{|c|}{ Resist. à Compressão } \\
\hline & $\begin{array}{c}\# 20 \\
0\end{array}$ & $\begin{array}{c}\# 32 \\
5\end{array}$ & & & Início & Fim & & $\begin{array}{c}1 \\
\text { Dia }\end{array}$ & $\begin{array}{c}3 \\
\text { dias }\end{array}$ & $\begin{array}{c}7 \\
\text { dias }\end{array}$ & $\begin{array}{l}28 \\
\text { dias }\end{array}$ \\
\hline $\mathrm{g} / \mathrm{cm}^{3}$ & \multicolumn{2}{|c|}{$\%$} & $\mathrm{~cm}^{2} / \mathrm{g}$ & $\%$ & \multicolumn{2}{|c|}{$\min$} & $\mathrm{mm}$ & \multicolumn{4}{|c|}{$\mathrm{MPa}$} \\
\hline 3,05 & 0,00 & 0,36 & $\begin{array}{c}4538,1 \\
8\end{array}$ & 30,04 & $\begin{array}{c}221,3 \\
6\end{array}$ & $\begin{array}{c}287,0 \\
5\end{array}$ & 0,32 & $\begin{array}{c}25,2 \\
8\end{array}$ & $\begin{array}{c}36,5 \\
3\end{array}$ & $\begin{array}{c}41,6 \\
6\end{array}$ & $\begin{array}{c}48,0 \\
6\end{array}$ \\
\hline
\end{tabular}

A massa específica média do pó de cerâmica vermelha empregado neste estudo é $2,53 \mathrm{~g} / \mathrm{cm}^{3}$. Este dado foi utilizado para o cálculo da quantidade de material a ser empregado no ensaio de determinação do índice de atividade pozolânica com cal.

A composição química do material cerâmico está apresentada na Tabela 4. O material atendeu a todos os requisitos químicos especificados pela NBR 12653 [17].

Tabela 4: Resultados da composição química do material cerâmico.

\begin{tabular}{c|c|c|c|c|c|c|c|c|c}
\hline \multicolumn{1}{c}{ Composição química, em \% } \\
\hline $\mathrm{SiO}_{2}$ & $\mathrm{CaO}$ & $\mathrm{Fe}_{2} \mathrm{O}_{3}$ & $\mathrm{Al}_{2} \mathrm{O}_{3}$ & $\mathrm{~K}_{2} \mathrm{O}$ & $\mathrm{SO}_{3}$ & $\mathrm{TiO}_{2}$ & $\mathrm{ZnO}$ & $\mathrm{MnO}$ & Álcalis totais \\
\hline 55,32 & 0,19 & 5,27 & 35,5 & 1,28 & 1,23 & 1,09 & 0,01 & 0,04 & 0,84 \\
\hline
\end{tabular}

$\mathrm{Na}$ Figura 1 está apresentado o resultado de DRX. Foram encontrados picos predominantemente referentes ao quartzo $\left(\mathrm{SiO}_{2}\right)$, com pequenas quantidades de caulinita $\left(\mathrm{Al}_{2} \mathrm{Si}_{2} \mathrm{O}_{5}(\mathrm{OH})_{4}\right)$, muscovita $\left(\mathrm{KAl}_{2} \mathrm{Si}_{3} \mathrm{AlO}_{10}(\mathrm{OH}, \mathrm{F})_{2}\right)$, óxido de ferro $\left(\mathrm{Fe}_{2} \mathrm{O}_{3}\right)$ e óxido de cálcio $(\mathrm{CaO})$. O material cerâmico não apresenta halo amorfo, não podendo neste caso ser, por este ensaio, atribuído potencialidade pozolânica ao material. 


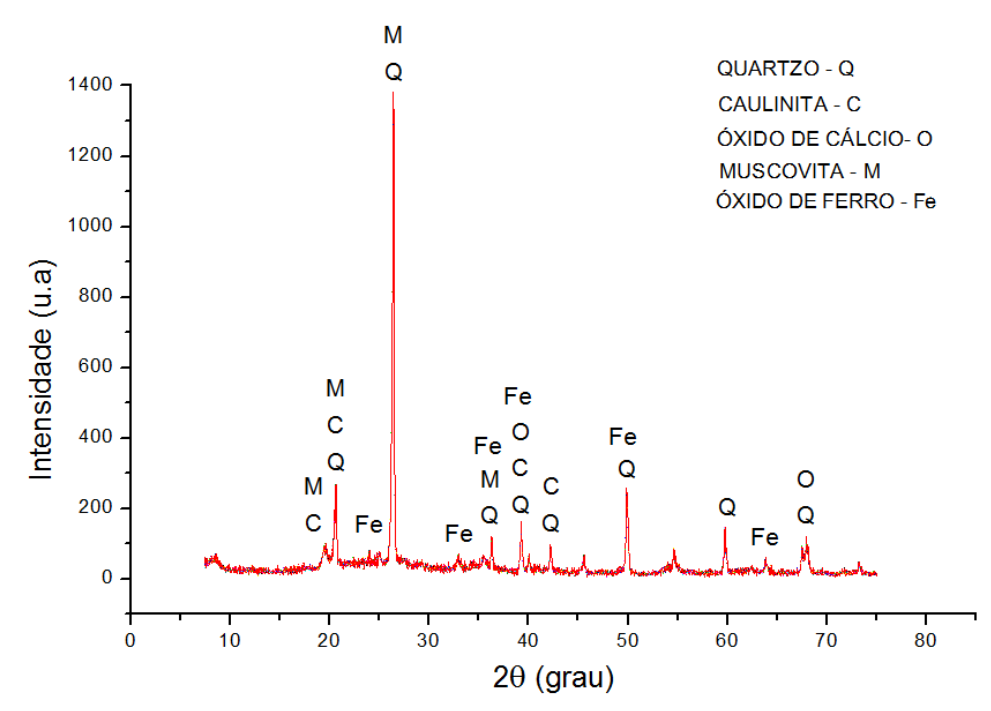

Figura 1: Difratograma de raios-X da amostra de material cerâmico.

O material cerâmico apresentou o consumo de $395 \mathrm{mg} \mathrm{Ca}(\mathrm{OH}) 2 / \mathrm{g}$ amostra, pelo método de Chapelle modificado, conforme a norma NBR 15895 [9]. O consumo mínimo atribuído a materiais pozolânicos é de $330 \mathrm{mg} \mathrm{CaO} / \mathrm{g}$ pozolana, o que corresponde por estequiometria a $436 \mathrm{mg} \mathrm{Ca}(\mathrm{OH}) 2 / \mathrm{g}$ pozolana [18]. O resíduo de cerâmica vermelha apresentou abaixo do mínimo, não podendo então ser classificado como pozolana. O resultado do ensaio Chapelle corrobora o estudo de Gobbi [18], onde quanto maior o tempo de moagem, ainda mais quando associado à calcinação, maior o teor de hidróxido de cálcio fixado, indicando maior reatividade.

A Figura 2 apresenta os resultados de resistência à compressão obtidos no ensaio de índice de atividade pozolânica com cal. A argamassa apresentou valores abaixo do limite da norma de 6,0 MPa determinado pela NBR 12653 [17], indicando que o material cerâmico não é classificado como adição mineral pozolânica. Este resultado também é coerente com o estudo realizado por Gobbi [18], que observou um aumento do valor desta propriedade com aumento no tempo de moagem, aliado ao fato de o material ter sido calcinado.

No presente estudo o material não foi moído no moinho de bolas e nem calcinado, apresentando resultados inferiores ao de Gobbi [18]. Optou-se por não fazer a moagem e a calcinação do material pela demanda energética que estes processos demandam, fugindo das questões ambientais relacionadas à redução o impacto gerado por este passivo ambiental. Outro aspecto relevante é que durante o uso de agregados reciclados, a fração pulverulenta é adicionada as misturas cimentícias na forma in natura, sendo então relevante esta análise sem manipulação do material cerâmico. 
BREKAILO, F.; PEREIRA, E.; PEREIRA, E., POTENCIAL POZOLÂNICO DO PÓ DE CERÂMICA VERMELHA E SEU EFEITO MITIGADOR DO ATAQUE POR SULFATOS DE SÓDIO EM BARRAS DE ARGAMASSA. $2{ }^{\circ}$ Simpósio Paranaense de Patologia das Construções (2 SPPC), artigo 2SPPC1018, pp. 213-223, 2017. DOI: 10.4322/2SPPC.2017.018

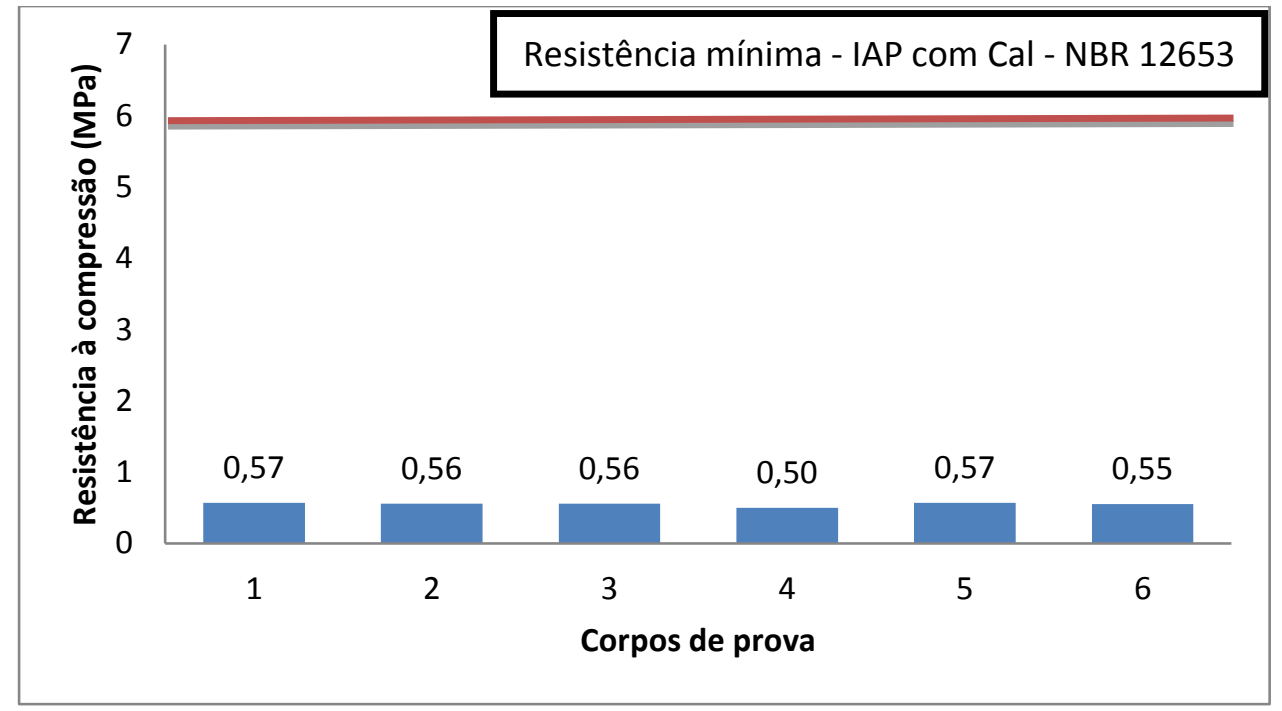

Figura 2: Resultados de resistência à compressão obtidos do IAP com cal e limite imposto pela NBR 12653 [17].

Já dos resultados de resistência à compressão obtidos no ensaio de índice de desempenho com cimento, apresentados na Figura 3, nenhuma afirmação pode ser feita, pois a análise do desvio relativo máximo apresentou valor maior que $6 \%$, fato que persistiu mesmo com a eliminação do valor discrepante, eliminando, portanto, todos corpos de prova. O fato aconteceu tanto para a argamassa sem como para a argamassa com substituição do material cerâmico. O ensaio será refeito, conforme orientação da NBR 7215 [16].

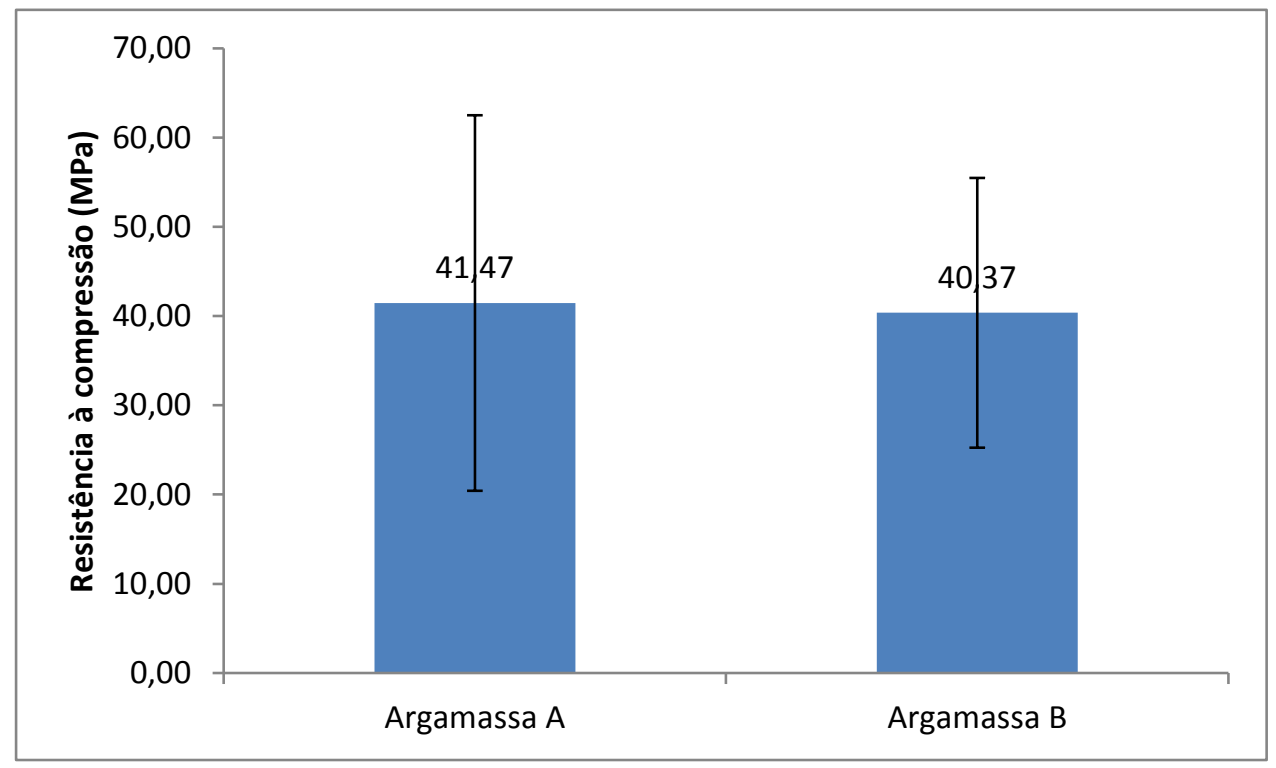

Figura 3: Resultados de resistência à compressão obtidos do ID com cimento.

A expansão resultante das barras da argamassa padrão e das argamassas com diferentes porcentagens de substituição expostas à solução de sulfato de sódio está apresentada na Figura 4, conforme NBR 13583 [12]. Os resultados mostram que com as substituições a expansão resultante aumentou, evidenciando que a adição do material cerâmico não possui potencial em mitigar o ataque por íons sulfato. 
BREKAILO, F.; PEREIRA, E.; PEREIRA, E., POTENCIAL POZOLÂNICO DO PÓ DE CERÂMICA VERMELHA E SEU EFEITO MITIGADOR DO ATAQUE POR SULFATOS DE SÓDIO EM BARRAS DE ARGAMASSA. $2^{\circ}$ Simpósio Paranaense de Patologia das Construções (20 SPPC), artigo 2SPPC1018, pp. 213-223, 2017. DOI: 10.4322/2SPPC.2017.018

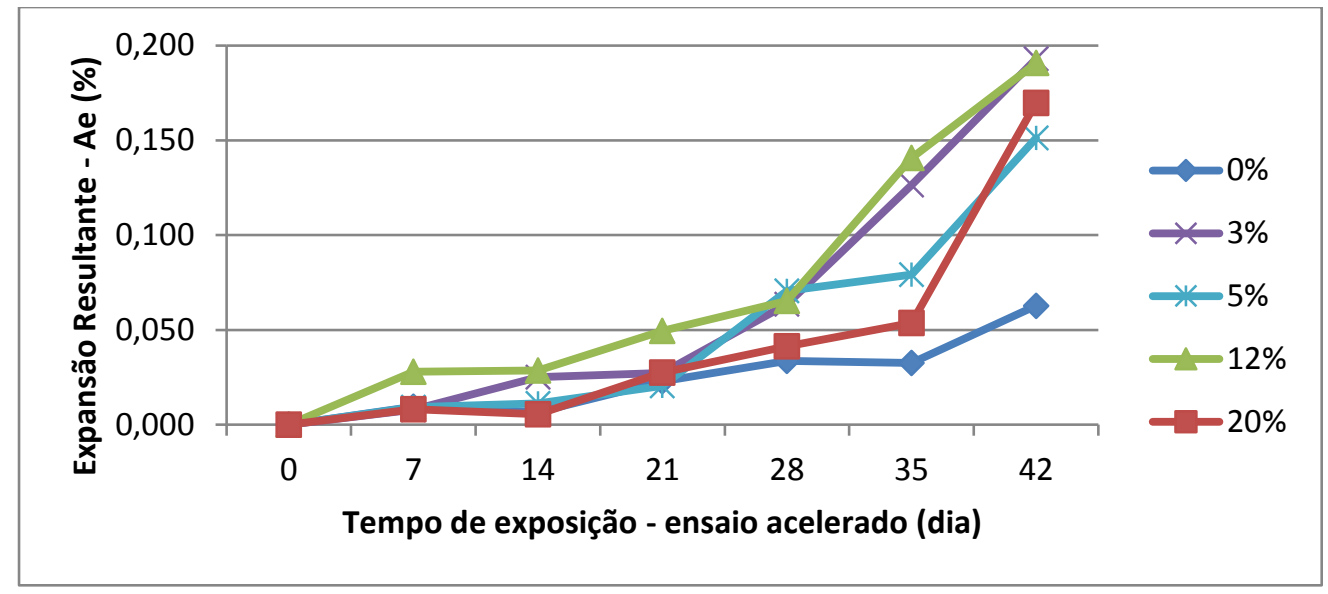

Figura 4: Expansão das argamassas contendo diferentes porcentagens da adição mineral na composição do material ligante, nas idades de $0,7,14,28,35$ e 42 dias, conforme método de ensaio NBR 13583 [12].

Marciano, 1993 [apud 3] propõe que aos 42 dias a expansão resultante limite é de $0,030 \%$ e para valores abaixo deste limite a argamassa pode ser considerada resistente ao ataque por sulfatos. Como mostrado na Figura 5, a argamassa de referência não é resistente ao ataque por sulfatos, apresentando valor de expansão superior a $0,030 \%$, e nenhuma das porcentagens de substituição apresentou uma redução capaz de atingir o limite proposto, pelo contrário, aumentaram o valor da expansão resultante, deixando este valor ainda mais distante de $0,030 \%$.

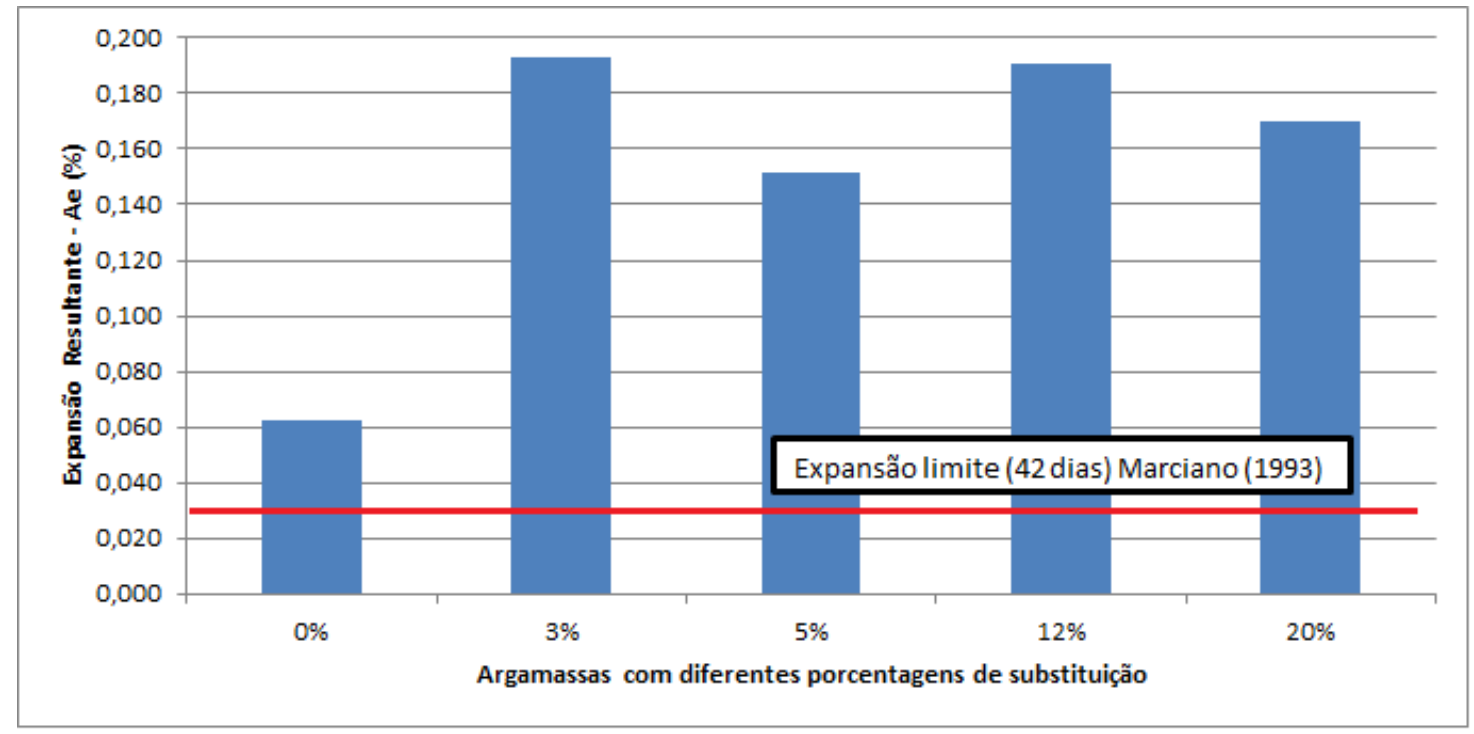

Figura 5: Expansão resultante, aos 42 dias, das argamassas contendo diferentes porcentagens da adição mineral na composição do material ligante, conforme recomendações da NBR 13583 [12], e limite de expansão resultante proposto por Marciano, 1993 [apud 3]

Visando uma avaliação mais completa da expansão das barras, as leituras continuaram além dos 42 dias. Desta forma, foi possível observar todas as barras imersas na solução de sulfato de sódio iniciarem a apresentar fissuras e a forma destas fissuras. A Figura 6 mostra algumas das fissuras apresentadas pelas argamassas com 12 e $20 \%$ de substituição da adição mineral na composição do 
BREKAILO, F.; PEREIRA, E.; PEREIRA, E., POTENCIAL POZOLÂNICO DO PÓ DE CERÂMICA VERMELHA E SEU EFEITO MITIGADOR DO ATAQUE POR SULFATOS DE SÓDIO EM BARRAS DE ARGAMASSA. $2{ }^{\circ}$ Simpósio Paranaense de Patologia das Construções (2० SPPC), artigo 2SPPC1018, pp. 213-223, 2017. DOI: 10.4322/2SPPC.2017.018

material ligante imersas em solução de sulfato de sódio. As fissuras iniciaram aos 35, 56, 63, 63 e 98 dias para as argamassas com substituição de 20, 12, 5, 3 e 0\%, respectivamente, e de forma muito singela nestas idades para os traços de 3 e $0 \%$. Percebe-se então que, quanto maior a porcentagem de substituição, antes iniciaram as fissuras, indicando que as argamassas ficaram mais frágeis.
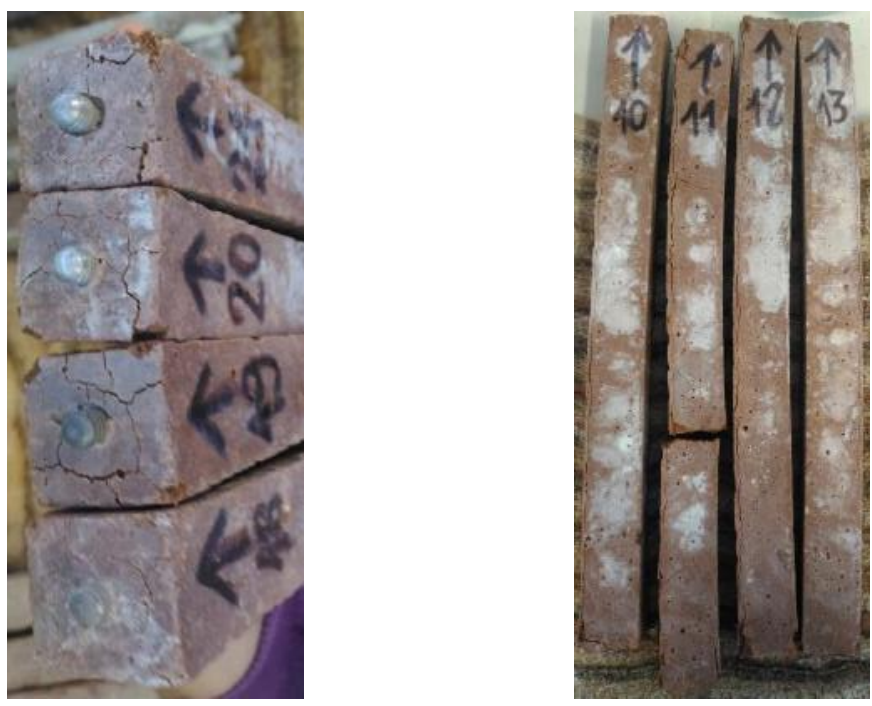

Figura 6: Fissuras nas barras de argamassas imersas em solução de sulfato de sódio: (a) barras argamassas com 12\% de substituição; (b) barras argamassas com $20 \%$ de substitução.

O uso da adição de cerâmica aumentou a expansão das barras de argamassa expostas à solução de sulfato de sódio possivelmente pelo fato da adição aumentar a porosidade da argamassa, pois o material cerâmico não é capaz de realizar as reações pozolânicas que modificariam a microestrutura da matriz e, desta forma, alterariam o comportamento da argamassa frente à ação dos ínos sulfato. Quanto mais porosa a matriz, maior 0 ataque por sulfatos de origem externa. Como no ataque a argamassa tem seus poros preenchidos com etringita, que possui volume maior que os compostos que substituiu, a expansão resultante nestas argamassas é maior. As barras com substituição apresentaram maior expansão e tiveram seus poros preenchidos com uma quantidade maior de etringita, como mostra as análises das micrografias das argamassas mostradas na Figura 7. 

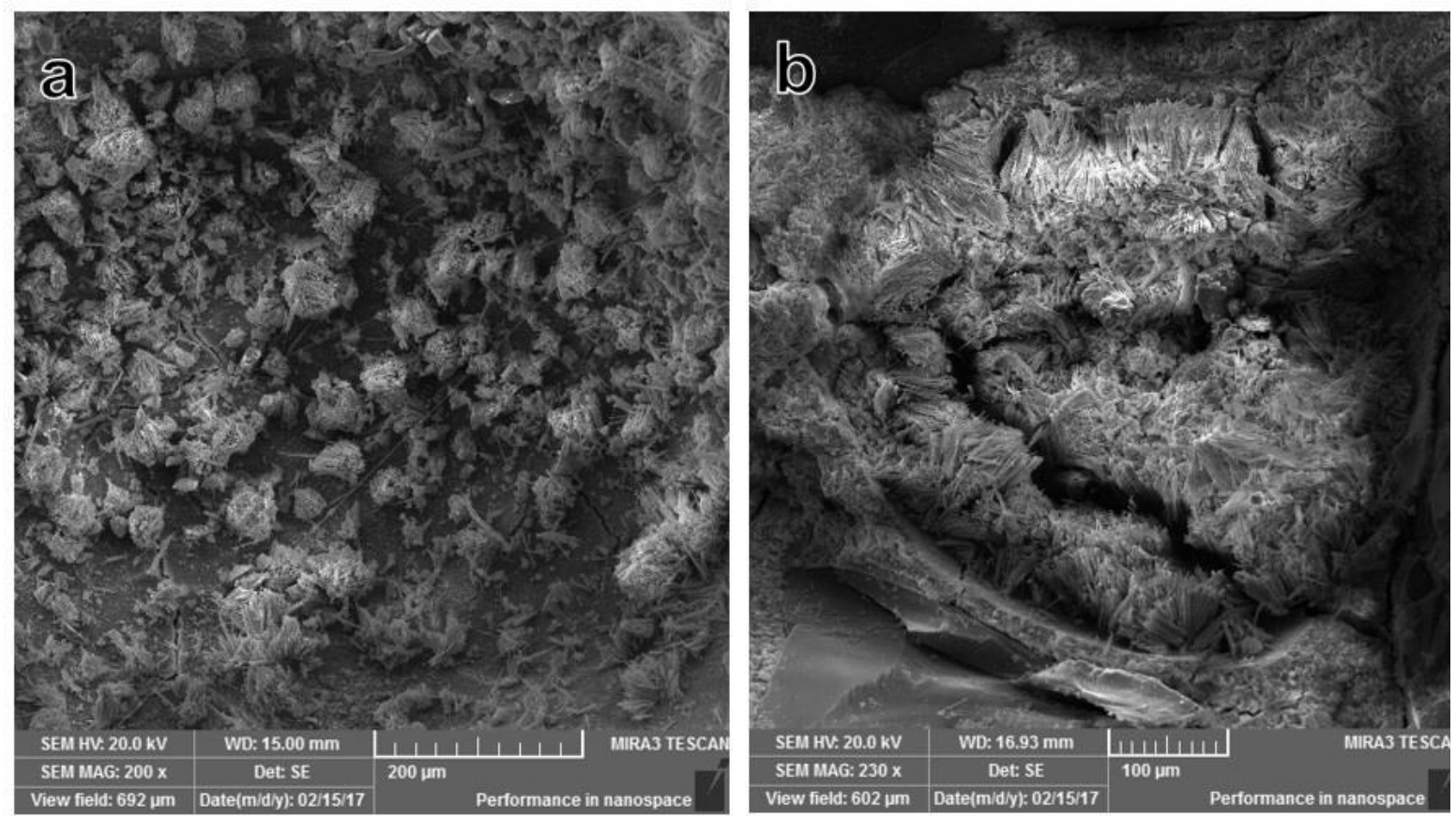

Figura 7: Microestrutura de argamassa imersa em solução de sulfato de sódio aos 100 dias, evidenciando a presença de cristais aciculares de etringita: (a) sem adição; (b) 20\% de substituição do cimento por pó de cerâmica vermelha.

\section{Conclusão}

O pó de cerâmica vermelha estudado atendeu aos requisitos químicos para ser considerado como pozolana. Apesar deste resultado positivo, apresentou no ensaio de Chapelle modificado valor abaixo do mínimo atribuído as pozolanas, não atingiu a resistência à compressão mínima no ensaio de IAP com cal e não apresentou resultados que indiquem reatividade pozolânica no DRX, não podendo, portanto, ser classificado como adição pozolânica.

Além de não ser classificado como pozolana, o material não apresentou potencial de mitigação no ataque por sulfatos em nenhuma das porcentagens de substituição da adição mineral na composição do material ligante, e quanto maior a porcentagem de substituição as argamassas ficaram mais frágeis, apresentando fissuras em idades menores.

\section{Agradecimentos}

A Fundação Araucária pelo apoio financeiro através da bolsa de estudos. Ao laboratório multiusuários - CLABMU da UEPG. Ao Instituto LACTEC e a Universidade Federal do Paraná pela colaboração durante o desenvolvimento deste trabalho. 
BREKAILO, F.; PEREIRA, E.; PEREIRA, E., POTENCIAL POZOLÂNICO DO PÓ DE CERÂMICA VERMELHA E SEU EFEITO MITIGADOR DO ATAQUE POR SULFATOS DE SÓDIO EM BARRAS DE ARGAMASSA. $2^{\circ}$ Simpósio Paranaense de Patologia das Construções (2० SPPC), artigo 2SPPC1018, pp. 213-223, 2017. DOI: 10.4322/2SPPC.2017.018

\section{Referências}

[1] MEHTA, P. K.; MONTEIRO, P. J. M. Concreto: estrutura, propriedades e materiais. 3a Edição. São Paulo: IBRACON, 2008.

[2] NEVILLE, A. M. Propriedades do concreto. 5a Edição. Porto Alegre: Bookman, 2016.

[3] HOPPE FILHO, J.; SOUZA, D. J.; MEDEIROS, M. H. F. de; PEREIRA, E.; PORTELA, K. F.. Ataque de matrizes cimentícias por sulfato de sódio: adições minerais como agentes mitigadores. Cerâmica 61, 168-177. 2015.

[4] NEVILLE, A. M.; BROOKS, J. J.. Tecnologia do concreto. 2a Edição. Porto Alegre: Bookman, 2013.

[5] HOPPE FILHO, J.. Efeitos da adição de cal hidratada sobre a permeabilidade ao oxigênio e absorção capilar de concreto com altos teores de adições minerais. Dissertação (Mestrado) - Universidade Federal de Santa Maria. Santa Maria, 2002.

[6] MORAES, R. C.. Efeitos físicos e pozolânicos das adições minerais sobre a resistência mecânica do concreto. Dissertação (Mestrado) - Universidade Federal de Santa Maria. Santa Maria, 2001.

[7] MEDEIROS, M. H. F.[; SOUZA, D. J.; HOPPE FILHO, J.; ADORNO, C. S.; QUARCIONI, V. A.; PEREIRA, E. Resíduo de cerâmica vermelha e fíler calcário em compósito de cimento Portland: efeito no ataque por sulfatos e na reação álcali-sílica. Matéria (Rio J.) vol.21 no. 2 Rio de Janeiro Apr./June 2016.

[8] ASSOCIAÇÃO BRASILEIRA DE NORMAS TÉCNICAS. NBR NM 23: Cimento portland e outros materiais em pó - Determinação da massa específica. Rio de Janeiro, 2000.

[9] NBR 15895: Materiais pozolânicos - Determinação do teor de hidróxido de cálcio fixado - Método Chapelle modificado. Rio de Janeiro, 2010.

[10] _. NBR 5751: Materiais pozolânicos — Determinação da atividade pozolânica - Índice de atividade pozolânica com cal — Método de ensaio. Rio de Janeiro, 2012.

[11] NBR 5752: Materiais pozolânicos — Determinação do índice de desempenho com cimento Portland aos 28 dias. Rio de Janeiro, 2014.

NBR 13583: Cimento Portland - Determinação da variação dimensional de barras de argamassa de cimento Portland expostas à solução de sulfato de sódio. Rio de Janeiro, 2014.

Janeiro, 2012.

NBR 7211: Agregados para Concreto - Especificação. Rio de

NBR 15116: Agregados reciclados de resíduos sólidos da construção civil - Utilização em pavimentação e preparo de concreto sem função estrutural . Rio de Janeiro, 2004. 
BREKAILO, F.; PEREIRA, E.; PEREIRA, E., POTENCIAL POZOLÂNICO DO PÓ DE CERÂMICA VERMELHA E SEU EFEITO MITIGADOR DO ATAQUE POR SULFATOS DE SÓDIO EM BARRAS DE ARGAMASSA. $2^{\circ}$ Simpósio Paranaense de Patologia das Construções (2० SPPC), artigo 2SPPC1018, pp. 213-223, 2017. DOI: 10.4322/2SPPC.2017.018

[15] NBR 7214: Areia Normal para ensaio de Cimento. Rio de Janeiro, 2009.

[16] N _ NBR 7215: Cimento Portland - Determinação da resistência à compressão, 1996.

[17] _ _ NBR 12653: Materiais pozolânicos. Rio de Janeiro, 2012.

[18] GOBBI, A.. Atividade Pozolânica de Adições Minerais pelas NBR 5751/2012 e NBR 5752/2012: uma análise crítica a partir de métodos complementares. Dissertação (Mestrado) - Universidade Federal do Paraná. Curitiba, 2014. 